\title{
Research in Dentistry: a Way Less Voyaged?
}

\author{
Satyawan Damle* \\ Maharishi Markandeshwar University, India \\ *Corresponding author: Satyawan Damle, Maharishi Markandeshwar University, Mullana, Ambala, Haryana-133207, India
}

Submission: 㘹 May 28, 2018; Published: 些 May 31, 2018

\section{Introduction}

No invention could have been possible had the human brain have been without the natural instinct of exploration, and search scrutiny. This human impulse has urged and led man to dig out probabilities of achieving excellence, through research and development. Eminent academicians and educationists have laid emphasis on research for better career progression and growth. In order to stand abreast with the challenges of modern times, research can play an important role in strengthening our development. Scientists have made amazing contributions to the advancement of science and technology all over the world. Also, there is no qualm that creativity is the most important human source of all. Without creativity, there would be no advancement and the continual discoveries and inventions in the field of medical science have demonstrated relief to humanity. It has led to low impermanence rate and has increased life expectancy. Penicillin was discovered. The causes of smallpox, malaria, and tuberculosis were acknowledged and their remedies worked upon and small pox, polio, plague, and cholera have been almost eliminated from the face of the earth.

In dentistry and oral health, a plethora of discoveries and research is conceded. Centuries ago, restoration of decayed teeth was difficult; therefore, extraction of decayed teeth was the only option. Then, it was an era of simple restoration or filling of decayed teeth. Restorative dentistry has traversed through the different phases of evolution and evaluation, and the field has been revolutionized with a constant advent of newer and newer restorative materials, with each passing span. Until now, one of the most bewildering issues in dentistry revolves around the use of different types of materials used for filling of teeth. Hence the supremacy of human mind is difficult to assess. Humanity has a constant thrust to search, research, and to find ways and means for the betterment of human welfare. The advancements of today might become the fortunes of tomorrow. The plunge and hunger for new inventions should solely be attributed and directed toward the welfare of the human race.
A historical appraisal of beauty reveals that man has succumbed to the power of beauty and its effect upon us. It can be aptly said that if beauty is power, a smile is its sword. In modern society, as an attractive smile is highly desired for today's dental patient, demand for dental treatment has shifted from functional dentistry to aesthetic dentistry. Aesthetic dentistry is the art of dentistry in the purest form. The purpose is not to disadvantage function but to use it as foundation of aesthetics.

However, the Dental and Oral Health Research scenario is in contrast to the Medical stream, as limited research is being carried out in dentistry. Whatever little research is undertaken is carried out by postgraduate scholars, it being a mandatory part of their study course. There are very few articles with a citation index and an impact factor, as compared to the medical field. The science of Medicine/Dentistry and the art of healing go hand in hand, complementing each other. It is the moral responsibility of Health/ Oral Health professionals to keep both facets properly balanced. Hence, senior researchers and clinicians have to be careful that research and patient care go side-by-side. Certainly, dentistry is at the stage of growth and development, wherein, a research paradigm must be established, so that the research is properly conducted. Creditable studies must be undertaken and their results must be verified, to validate their use for the well-being of humans. If we do not pay due attention to the aspect of research in dentistry, the future of this branch will be dismal and directionless also the dynamic process of change clearly affects nearly all aspects of the dental professional, in dental education and dental research. Dental publications are not an exception. When we compare them with those of the past, we will realize that the number of publications has increased tremendously and the standard and quality has improved considerably. Expectations from dental journals have increased because of the introduction of new concepts such as the impact factors. Unless and until research is made compulsory and mandatory it is difficult, rather, impossible, to achieve success in our aims and objectives of leading dentistry at a global level. 
Creative Commons Attribution 4.0 International License

For possible submissions Click Here

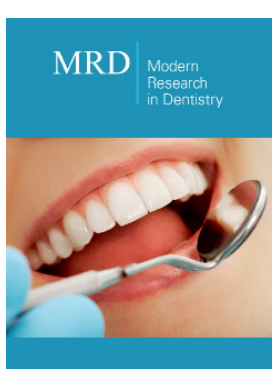

\section{Modern Research in Dentistry}

\section{Benefits of Publishing with us}

- High-level peer review and editorial services

- Freely accessible online immediately upon publication

- Authors retain the copyright to their work

- Licensing it under a Creative Commons license

- Visibility through different online platforms 